(C2016, Elsevier. Licensed under the Creative Commons Attribution-NonCommercialNoDerivatives 4.0 International http://creativecommons.org/about/downloads

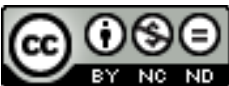




\title{
Disruptive innovation, managerial cognition, and technology competition outcomes
}

Riccardo Vecchiato

\begin{abstract}
In this paper we explore why incumbent firms fail to identify and address new markets in the face of disruptive technologies. We cross research on disruptive innovation with research on managerial cognition by exploring the role of managerial beliefs about customer needs in directing the search for new markets and product features. We show that a primary reason why incumbents lose their leadership is the inability to recognize either the rising 'social' market, where customers use products for fulfilling their need for friendship, or the 'esteem' market, where customers use products for fulfilling their need for achievement. We thus advance the disruptive innovation theory with regard to both the explanation and the anticipation of technology competition outcomes.
\end{abstract}

Running Head: Disruptive technologies and cognition

Keywords: Disruptive innovation; cognition; social market; esteem market; competition outcomes; established firm failure. 


\section{Introduction}

Since professor Clayton Christensen first published research on disruptive technologies in 1997, his work has had a dramatic impact on business practice: disruptive innovation is now a common term of art. This theory played a key role in reigniting debate within academia on the difficulties of incumbent firms to respond to discontinuous technological changes.

Christensen's work has been cited extensively by scholars in diverse disciplines and research fields, including marketing, strategy, and technology and innovation management. However, despite the growing popularity of Christensen's work, there seems to be still a lack of understanding of the effects of disruptive technologies on firms and competition outcomes (Hang et al., 2014; Keller and Husig, 2009; Walsh et al., 2005).

In this paper we explore how managerial cognition influences the market choices of organizations and thereby affects their long term performance in the face of disruptive technologies. We address the following question: How do managerial beliefs about customer needs affect the capability of organizations to identify new markets in the face of disruptive technologies?

This paper is based on an in-depth, multiple case study of the mobile communication and imaging (printing) industries. Based on the lessons derived, we introduce the concepts of 'social' and 'esteem' markets: we show that the incumbent firms (Motorola and Kodak) failed to to identify these emerging markets, and we show the role of managerial beliefs in explaining their failure. We then apply our resulting conceptual framework to the smartphone industry: we consider which operating system will ultimately succeed, by comparing Microsoft's recently launched Windows 10 Mobile with Apple's iOS and Google's Android. In this way we try to contribute to the disruptive innovation theory with regard to both the explanation and the anticipation of technology competition outcomes (Danneels, 2004; Linton, 2004: Kostoff et al., 2004). 


\section{Disruptive technologies, managerial cognition, and market choices}

\subsection{Disruptive technologies}

Research on disruptive technologies emphasizes the influence of customer needs on industry dynamics and technology competition outcomes (Abernathy and Clark, 1985; Phillips, 2001). The concept of disruptive technologies was originally introduced by Christensen (1997) and Christensen and Bower (1996): these are technologies that enable a new set of product features from those associated with mainstream technologies, and are initially inferior to the latter ones along one or two attributes ('mainstream features') that are particularly important to mainstream customers. Thus, in the early stage of their life cycle, disruptive technologies only serve niche segments that value their new kinds of attributes. However, as subsequent developments raise the disruptive technology's performance in mainstream attributes to a level sufficient to satisfy mainstream customers, the disruptive technology eventually ‘invades' mainstream markets. The most powerful analytical tool Christensen (1997) provides for identifying a disruptive technology is his diagram which jointly plots for mainstream attributes: i) the performance trajectory provided by the disruptive technology; ii) and the performance trajectory demanded by the mainstream market. Since the performance trajectory provided by the disruptive technology is steeper than the performance trajectory demanded by the mainstream market, technology disruption occurs when the two intersect.

\subsection{Disruptive technologies and original explanations for the failure incumbents}

Christensen's (1997) original explanation for the failure of leading firms draws on the resource dependence theory: he argues such failure is the result of incumbents' resource allocations processes, where incentive structures based on target product sales and margins lead them to disregard disruptive technologies and intensify their commitment to mainstream technologies. 
However, later on scholars argued that the failure of incumbents may be due not to their inability to invest and adopt disruptive technologies in a timely manner, but rather to their inability to commercialize them successfully - i.e. to find new markets and provide customers with the new products and product features they actually want (Groen et al., 2008). According to Danneels (2004), many incumbents have been able to develop working prototypes of products embedding an emerging disruptive technology, thus demonstrating that they have the necessary R\&D capabilities to innovate. However, these incumbents lacked what Danneels (2004: 254) calls "the customer competence" to identify new customer groups that they had not served before. As he further developed the disruptive innovation theory, Christensen himself (2000, p. 58) revised his initial arguments for explaining the failure of incumbent firms, by noting that: "Professor Rebecca Henderson pointed out to me that this tendency always to take new technologies to mainstream customers reflects a rather narrow marketing competence - that although many scholars tend to frame the issue as one of technological competence, such inability to find new markets for new technologies may be a firm's most serious handicap in innovation" (italics in original). Christensen and Raynor (2003) and Christensen et al. (2004) thus urged incumbents' managers to broaden their marketing scope, by looking for emerging customer needs and new markets (market niches/market segments) related to these needs. Specifically, Christensen and colleagues claimed that traditional market segmentation processes, which are based on such criteria as age, geographic regions or income, are likely to be of little use (for a review of market segmentation criteria see Dickson and Ginter, 1987). They argued instead that people have 'jobs' which arise regularly and which they have to get done: these jobs represent the basic needs that customers try to satisfy by means of the products they use in their everyday life. These jobs, i.e. these basic everyday needs, should constitute the cornerstone for the search for emerging markets in the face of disruptive technologies. 


\subsection{A new perspective on disruptive technologies and the failure of incumbents:}

\section{the role of cognition}

As they explore the likely reasons why incumbent firms lack the marketing competence to identify new markets for disruptive technologies, Hendersen (2006) and Danneels (2004) point to the mainstream research field of managerial cognition. This research field focuses on the role of managers' mental models/beliefs in explaining organizational responses to technological discontinuities (Garud and Rappa, 1994).

Because of their bounded rationality, managers must rely on simplified representations of the business environment in order to process information about new events (Simon, 1955). These imperfect representations form the basis for the development of the mental models and strategic beliefs that drive managerial decisions. They influence the manner in which managers frame external changes and thus how they search for responses to these changes (Tripsas and Gavetti, 2000; Kaplan, 2011). ${ }^{1}$

Managerial beliefs are usually based on historical experience as opposed to current knowledge of the environment (Kaplan and Tripsas, 2008). In changing industries, the influence of prior history often increases the difficulty that decision makers face when seeking to respond to new events, and this difficulty then often results in organizational inertia and poor performance. For instance, in the transition to digital imaging, Polaroid's commercialization strategy was driven and limited by beliefs resident in the analog photography business model (Tripsas and Gavetti, 2000). Similar effects have been found in

\footnotetext{
${ }^{1}$ Since the early 2000s, the concept of managerial beliefs has been developed and measured according to two dominant approaches. Based on extensive field studies, one research stream typically uses data gathered from semi-structured interviews and firm archives to retrospectively explain how managerial beliefs led to a focal event, such as bankruptcy of Polaroid Corporation (Tripsas and Gavetti, 2000). The second research stream seeks to explain variations in firms' strategies by exploring the variation of CEOs' strategic beliefs. These studies take publically available documents, such as letters to shareholders in a firm's annual reports, as the proxies for the strategic thinking of CEOs and employ content analysis to uncover themes pertaining to managerial cognition and strategy (Nadkarni and Barr, 2008; Eggers and Kaplan, 2009).
} 
the shift from print to online newspapers (Gilbert, 2006), in pharmaceutical firms' responses to the emergence of biotechnology (Kaplan et al., 2003), and in communications technology firms’ responses to fiber optics (Kaplan, 2008).

Hence, when analyzing the determinants of incumbents' behavior in response to disruptive changes, managerial cognition should have a major role (Osiyevskyy and Dewald, 2015). According to Danneels (2004) and Henderson (2006), incumbents' managers might not understand the implications of disruptive technologies because their views of the world are deeply entrenched and largely shaped by their prior experiences of technologies and markets. These scholars thereby strongly suggest to cross research on disruptive innovation with research on managerial cognition.

However, thus far we still know very little about the impact of managers' mental models on the strategic responses of incumbent firms to disruptive technologies (Osiyevskyy and Dewald, 2015). Our literature review uncovered a lack of empirical studies examining the relationship between managerial beliefs and the search processes for emerging markets. As such, there is a significant opportunity to expand our understanding of disruptive innovation and technology competition outcomes. In this paper we aim at seizing this opportunity. Our work is the first empirical study which crosses research on disruptive innovation with research on managerial cognition, by addressing the following question: How do managerial beliefs about customer needs affect the capability of organizations to identify new markets in the face of disruptive technologies?

Table 1 illustrates the main contribution of our work, by highlighting the novelty and uniqueness of our framework compared with previous studies of disruptive innovation. 
Table 1. Extant explanations for incumbents' failure in the face of disruptive technologies and novel contribution of this empirical study

\begin{tabular}{lccc}
\hline Late 1990s & $\begin{array}{c}\text { Extant literature: } \\
\text { mid 2000s - today }\end{array}$ & $\begin{array}{c}\text { Gap in literature addressed by } \\
\text { our research framework }\end{array}$ \\
\hline $\begin{array}{l}\text { Proposed } \\
\text { explanation for the } \\
\text { struggles of } \\
\text { incumbent firms }\end{array}$ & $\begin{array}{c}\text { Resource } \\
\text { allocation } \\
\text { processes }\end{array}$ & $\begin{array}{c}\text { Marketing } \\
\text { competence: lack of } \\
\text { capability to identify } \\
\text { new markets }\end{array}$ & $\begin{array}{c}\text { The role of managerial cognition in } \\
\text { explaining the responses of } \\
\text { incumbent firms: lack of empirical } \\
\text { studies }\end{array}$ \\
\hline Main authors & $\begin{array}{c}\text { (Christensen and } \\
\text { Raynor, 2003; }\end{array}$ & $\begin{array}{c}\text { How do managerial beliefs about } \\
\text { customer needs affect the capability } \\
\text { of organizations to identify new } \\
\text { markets in the face of disruptive } \\
\text { technologies? }\end{array}$ \\
\hline
\end{tabular}

The paper is structured as follows. In the next section we describe our research method. In the subsequent section we illustrate the market choices of Motorola and Kodak and we compare these choices with those made by their rivals, Nokia and HP. Then we outline our resulting conceptual framework on managerial belief, customer needs, and technology competition outcomes.

\section{Research Method}

We used a multiple-case research design (Eisenhardt, 1989): given the gap in extant literature and the open-ended nature of our research questions, we felt this methodological approach would be the most useful for expanding the disruptive innovation theory (Glaser and Strauss, 1967; Yin, 2003). Multiple cases allow a replication logic in which each is treated as an experiment, serving to confirm or disconfirm inferences drawn from the others (Eisenhardt and Grabner, 2007).

\subsection{Research setting}

Our research settings are the mobile communication and the imaging industries. We analyzed how Motorola and Nokia handled, between the early 1990s and the early 2000s, the transition 
from radio communication technologies (pagers, two-way radios, car phones) to cell phone technologies (1G and $2 \mathrm{G}$ wireless technologies) ${ }^{2}$ and how Eastman Kodak (Kodak) and Hewlett-Packard (HP) handled, between the early 2000s and the late 2000s, the transition from film technology to digital imaging. ${ }^{3}$ (Although Kodak offered a full range of products and services from image capture to image storage, manipulation, and transmission, in this paper we focus on image printing: this was a key business on which the company put a lot of effort).

$1 \mathrm{G} / 2 \mathrm{G}$ technologies and digital imaging are compelling examples of disruptive technologies (Christensen and Raynor, 2003; Christensen et al., 2004). In both industries the incumbent firm (i.e., the original leader) and the entrant firm (i.e., the rising leader) targeted very different markets and customer needs through their products: our case firms thus represent "polar" companies which are particularly suitable for observing contrasting patterns in the data (Eisenhardt and Grabner, 2007). Table 2 summarizes our empirical setting.

Table 2. Description of Case Studies

\begin{tabular}{|c|c|c|c|c|c|c|c|}
\hline Industry & Time & $\begin{array}{l}\text { Incum- } \\
\text { bent } \\
\text { firm }\end{array}$ & $\begin{array}{l}\text { Rising } \\
\text { leader }\end{array}$ & $\begin{array}{l}\text { Mainstream } \\
\text { technologies/ } \\
\text { products }\end{array}$ & $\begin{array}{c}\text { Disruptive } \\
\text { techno- } \\
\text { logies }\end{array}$ & $\begin{array}{c}\text { Products } \\
\text { provided } \\
\text { by the } \\
\text { original } \\
\text { leader }\end{array}$ & $\begin{array}{l}\text { Products } \\
\text { provided } \\
\text { by the } \\
\text { rising } \\
\text { leader }\end{array}$ \\
\hline $\begin{array}{l}\text { Mobile } \\
\text { Commu- } \\
\text { nication }\end{array}$ & $\begin{array}{c}\text { Early } \\
1990 \text { s- } \\
\text { early } \\
2000 \text { s }\end{array}$ & $\begin{array}{l}\text { Moto- } \\
\text { rola }\end{array}$ & Nokia & $\begin{array}{c}\text { Radio } \\
\text { communication } \\
\text { technologies } \\
\text { (pagers, two- } \\
\text { way radios, car } \\
\text { phones) }\end{array}$ & $\begin{array}{c}1 \mathrm{G} \text { and } 2 \mathrm{G} \\
\text { wireless } \\
\text { techno- } \\
\text { logies }\end{array}$ & $\begin{array}{c}\text { Clamshell } \\
\text { phones }\end{array}$ & $\begin{array}{c}\text { Candybar } \\
\text { phones }\end{array}$ \\
\hline $\begin{array}{l}\text { Imaging } \\
\text { (printing) }\end{array}$ & $\begin{array}{l}\text { Early } \\
2000 s- \\
\text { to date }\end{array}$ & $\begin{array}{c}\text { Eastman } \\
\text { Kodak } \\
\text { (Kodak) }\end{array}$ & $\begin{array}{l}\text { Hewlett } \\
\text { Packar } \\
\text { d (HP) }\end{array}$ & Film imaging & $\begin{array}{l}\text { Digital } \\
\text { Imaging }\end{array}$ & $\begin{array}{l}\text { Digital } \\
\text { kiosks }\end{array}$ & $\begin{array}{c}\text { Data } \\
\text { printers for } \\
\text { home/office } \\
\text { use }\end{array}$ \\
\hline
\end{tabular}

\footnotetext{
${ }^{2}$ The 1G (analog) first generation of wireless communication technology was launched in the early 1980s and gradually established through that decade. The second generation ( $2 \mathrm{G}$ - digital) was developed during the 1980s, and replaced 1G technology over the course of the 1990s. The first Global System for Mobile (GSM) network was launched in 1991; it quickly established as the main 2G standard.

${ }^{3}$ Digital imaging is the capture, manipulation, storage, transmission, and printing of images via digital technologies. Demand for digital imaging boomed in the early 2000s, despite first digital cameras arriving on the market in the late 1980s.
} 


\subsection{Data collection}

We focused our data collection on tracking major markets, products and product features, relying on two primary data sources: archives and interviews. We gathered extensive archival data for each firm - incumbents and challengers - exploiting both internal and external sources, including annual reports, press releases, internal reports and presentations, video and audio archives of executive presentations, internal memos, technical papers, media articles etc., (collected via tools such as ABI Inform), complemented with analyst reports and books about the firms (Steinbock, 2001). Relevant sources were high-tech magazines like 'PC Magazine' and 'PCWorld', as well as specialized web site like 'GSM Arena', which covered the evolution of the mobile communication and the imaging industries throughout the 1990s and 2000s. These sources thus provided useful information about the main products commercialized by each firm and their main features. Finally, leading research and consulting firms in high tech industries - i.e. Gartner and International Data Corporation (IDC) - and in the imaging business - i.e. PMA (Worldwide Community of Imaging Associations) and InfoTrends - provided extensive data about worldwide and regional market sales in our two case industries, and about the market shares of each of our selected companies. Semistructured interviews with internal and external informants were our second main data source. Internal informants included managers and executives selected according to their hierarchical and functional position and their direct involvement in the development and commercialization of the new technologies and products. External informants included senior executives from business partners and competitors, and industry specialists and consultants.

\subsection{Data analysis}

Data analysis was also highly iterative and used traditional case study research approaches 
(Yin, 2003). Our research question shaped our data collection plan and thus gave priorities to the analytical process, which was based on a cluster methodology where common words and topics were gradually identified (Aldenderfer and Blashfield, 1984). Cluster labels included managerial beliefs and markets (see Table 3 ). We followed an iterative process of cycling between theory, our data and the extant literature on innovation to refine our findings, relate them to existing theories, and clarify our contributions (Eisenhardt, 1989).

Table 3. Data Analysis

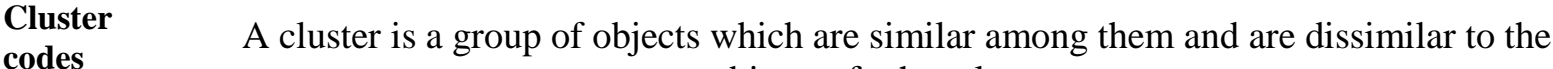
definition objects of other clusters.

\section{Results}

Notwithstanding that they developed the same new disruptive technologies, the incumbent firm and its challenger within each industry identified and addressed completely different markets and customer needs: they thus developed quite different products.

\subsection{Mobile communication (early 1990s - early 2000s)}

4.1.1 Motorola. Motorola managers firmly believed mobile phones responded to people's need to improve their efficiency and performance. A former senior director illustrated: "Mobile devices are meant to enable people to perform their work tasks while away from the office, thus improving the quality and amount of their outcomes. " Throughout the 1990s, Motorola's annual reports portrayed customers like top and middle managers, frontline employees, and professionals, using mobile phones for fulfilling the job of contacting colleagues from remote locations (e.g., travelling on a boat) with captions encapsulating what 
the company saw as its mission: "Making life more efficient". In the 1994 annual report's letter to stockholders, the President Galvin and CEO Tooker emphasized: “Our customers look to us for the tools for improving productivity. " (the original text highlights the word 'productivity'), while the 1997 letter repeats the same message: "We give people freedom, mobility and convenience. In doing so, we are building the tools that people need for success in the next century."

Motorola's target customers were "whoever could benefit from mobile phones to improve the productivity and achievement of their work activities", as a senior manager told us.

Motorola clearly identified weight as the key (mainstream) feature of its phones in serving its target customers; at the same time, it used both the $1 \mathrm{G}$ and $2 \mathrm{G}$ new wireless technologies to introduce - or substantially enhance - such mobile communication device attributes and functions as battery duration, phone book, answering machine, voice mail, call forwarding, vibrating 'vibracall' mode.

Two series of mobile phones - the MicroTAC and the StarTAC - provide the most compelling examples of the product strategy of Motorola. The MicroTAC was first launched as an analog version in 1989, with GSM-compatible versions following in 1994. These phones introduced an innovative design which allowed to save space and weight: Motorola engineers placed part of the phone's hardware (e.g., the mouthpiece) in a hinged section at its base. Such section could fold inward or outward as needed over the keypad, so reducing the phone size when it was not in use. When they were released, the MicroTAC models were by far the smallest and lightest phones available. The StarTAC, the successor to the MicroTAC released in early 1996, was the first ever 'clamshell' mobile phone. While the MicroTAC's shell folded out from below the keypad, the StarTAC folded from the top down over the display: optimized for ease handling and compact size, it was another breakthrough design concept in the industry. To introduce the StarTAC, the 1995 annual report shows a 
businessman talking on the phone in front of the Pantheon, while the accompanying text reads:

The new StarTAC wearable cellular phone brings the Space Age to the ancient Rome. Soon to be available in Italy, the StarTAC is the world's smallest and, at 3.1 ounces, the world's lightest cellular phone. [...] At just 3.1 ounces, the new StarTAC cellular phone can literally be "worn" by consumers in need of reliable but unobtrusive communications.

4.1.2 Nokia. In contrast to Motorola, Nokia managers believed that customers used mobile phones as tools for fulfilling their social relationships. A senior manager explained:

In the early 1990s we decided to focus our core business in mobile communication. We felt there were tremendous opportunities for growth by expanding the boundaries of the industry. We committed to pioneer not just wireless technologies, but the human and social dimension of mobile communication,

while a sociologist who has served as an external consultant to Nokia concurred:

Nokia claims 'Connecting people' reflects the heart of the company's mission - to help people cultivate their social relationships via their mobile phones.

Throughout the 1990s, Nokia's annual reports showed pictures of people (like Motorola's target business users) using their mobile phones in order to stay in touch with family and friends while away from home - rather than for communicating with colleagues while away from office. In the 1995 annual report, an exemplar comic-strip story placed immediately after the CEO's letter to shareholders illustrated this social kind of use of mobile phones:

In the modern family, people do their own thing. Mum may be away on business, Dad's driving long distance, Junior's at home... but that doesn't mean you can't stay in touch". [...] Junior says: "My Mum's away on business. I sort of miss her". [...] Just then Mum calls [through its mobile device]: "Hi, how are you! Eating properly?" Junior replies "Er yes, we've got a freezer full of food..." (emphasis added)

The comic-strip's end- caption reinforced the company mission: "Nokia...connecting people".

In line with the different customers' need for mobile phones it identified, Nokia made completely different strategic choices from Motorola with regard to target products and product features. From the early/mid 1990s, Nokia introduced a very different set of product 
features, such as colorful and changeable covers, internal antennas, customizable ring tones and soft 'navi' keys (flexibly programmable keys which allow users to choose which functions they control). Compared with Motorola's MicroTAC and StarTAC series, Nokia's phones in particular emphasized large keypads and displays for writing text messages (SMS -short message service) easier. SMS represented a radically new pattern of communication, allowing people to communicate immediately and indirectly through a few words.

In providing these features, Nokia released relatively bulky products, which could not compete in terms of weight and size with Motorola's clamshell phones: Nokia's phones were candybar models (i.e. monoblock, taking the shape of a cuboid and having the display and keypad all on the same face), with a smooth, rounded and stylish look that rapidly became their hallmark. An internal Nokia Design Team report outlines the company's basic design principles as follows:

Less than a decade ago [mid 1990s] all mobile phones were black. Then Nokia introduced color to the products and everything changed. The mobile phone suddenly became a statement of one's personal style, communicating more about the owner's identity than any electronic product had done before. We were the first to introduce removable covers, enabling people to personalize the look of their phone in a few seconds. We created user interfaces easy to use and learn; display and key pads large enough for easy writing and reading and pleasant touch; size and shape that are comfortable.

Nokia launched a wide stream of representative models featuring these attributes throughout the 1990s: the 2100 (1994), the 3100 (1997), the 5110 (1997), the 3210 (1999), the 3310 (2000) and the 3410 (2001).

\subsection{Imaging (printing)}

4.2.1 Kodak. Managers at Kodak clearly conceived images as tools that customers used for cultivating their social relationships: images enabled people to keep their memories and share them with family and friends. The manager of a firm that partnered Kodak in developing digital products explained: 
You came across executives with different seniority and from different functions: you talk with them for a few minutes and you were soon convinced that they share a deep-rooted mission: to help people tell their personal stories.

This focus was very well illustrated by the introductory note to Kodak's 2001 annual report letter to shareholders:

For more than a century, our trusted products have helped people around the globe record and share what is important in their lives. Our current consumer advertising theme'Share moments. Share life.' - sums up the emotional appeal of our products and services. Capturing and sharing memories-from everyday moments to once-in-a-lifetime eventsfulfills a fundamental human need. No other consumer product category provides such an intensely personal value. Images are for sharing. They always have been and they always will be. And that's why there will always be a Kodak. (emphasis added)

Thus, when digital imaging emerged in the late 1990s, Kodak targeted the broad base of its traditional users of analog (film-based) photography in order to lead their transition to the new technology: Kodak's former Vice President Scott Auer pointed out that "More and more families are using digital cameras to archive memories". ${ }^{4}$ So Kodak made great efforts to develop completely new products and services across its whole value chain to provide customers (i.e., "people") with high quality digital pictures.

The case of imaging printing in particular is very telling. Throughout the late 1990s and 2000s, Kodak put most of its efforts into the business model of printing at retailers. ${ }^{5}$ The company offered two main processing solutions - mini-labs and kiosks - the latter one being the most relevant. Consistent with its longstanding motto 'You Press the Button, We Do the Rest', Kodak's kiosks enabled people to easily get best in class quality prints from their digital images. Vice President Scott Auer commented:

A significant amount of consumers are looking for digital printing solutions at retail offering immediate satisfaction in viewing and printing pictures, control over the quantity of pictures printed and the price you are willing to spend on prints, and mirrors

\footnotetext{
4 “Kodak makes it easier for consumers to print digital pictures. Expanded availability of Kodak Picture Maker Digital Printing Kiosks makes printing quality digital pictures at retail locations easier than ever" June 24, 2004; available on www.kodak.com, accessed December, 2008. Scott Auer is a past Kodak Vice President for Retail Imaging, Digital \& Film Imaging Systems.

${ }^{5}$ In the early 2000s, Kodak launched as well as small home and office printers optimized for digital picture making; however, the company soon dismissed such business in favor of kiosks and mini-labs. The company started again producing and marketing printers for home and office use in 2007.
} 
the behavior of consumers taking their film to a retail location for processing. ${ }^{6}$

4.2.2 HP. In contrast to Kodak, HP managers firmly believed that customers used images for fulfilling their creativity and inventiveness. Former CEO Carly Fiorina noted:

Digital photography is a digital, mobile, virtual process. ${ }^{7}$

The digital revolution has been called the creativity revolution, and I think we just saw an example of why, because in the digital age, if you can dream it - you can do it. If you can envision it-you can create it. If you can see it-you can shoot it. That's what digital technology is all about. There used to be a limit to creativity; there used to be a limit to what technology could help you do. In the digital age, the only limits we face are the limits of our own imagination. ${ }^{8}$

HP's 2001 annual report letter to shareholders stressed that:

Digital imaging encompasses more than just great digital cameras; it requires PCs, photo printers, software, computing infrastructure and an understanding of networking to build solutions that can allow people to take pictures, incorporate them in their work, print and email them reliably and archive them effectively. (emphasis added)

In contrast to Kodak's kiosks, throughout the 2000s HP thus established its 'Imaging and Printing Group - IPG' business unit and launched a wide array of versatile data printers for home and office making of digital images, like the 'Photosmart' (versatile machines optimized for images) and 'All-in-One' (printing, scanning, and copying machines) series. In order to allow “people to incorporate pictures in their work", HP's printers placed less emphasis on the quality of pictures: rather, other product features - like versatility, flexibility, speed, convenience, and most of all seamless integration with other PC files and PC applications - became crucial. For instance, the HP Photosmart 1315, which was released in 2001, included a CD with drivers for both Microsoft Windows and Apple Macintosh and could print text pages, black and color documents, and 8.5x11 - inch pictures at 2,400x1,200

\footnotetext{
${ }^{6}$ Kodak makes it easier for consumers to print digital pictures. Expanded availability of Kodak Picture Maker Digital Printing Kiosks makes printing quality digital pictures at retail locations easier than ever”, ibid.

${ }^{7}$ Carly Fiorina, 'From Creation to Consumption, the Future for Digital Revolutionaries', Consumer Electronic Show, Las Vegas, Nevada, January 8, 2004.

${ }^{8}$ Carly Fiorina, 'The digital experience journey'. HP Digital Experience press conference, Miami, Florida, August 27, 2004.
} 
DPI. ${ }^{9}$ The quality of these pictures thereby was relatively good but clearly inferior compared with Kodak's kiosks.

\section{A Framework for Social and Esteem Markets (Product Categories),}

\section{Managerial Beliefs, and Technology Competition Outcomes}

In the previous section we outlined the different markets and customer needs that incumbent firms and their challengers addressed in the face of disruptive technologies. Table 4 summarizes the empirical evidence from our case studies.

Table 4. Beliefs about customers needs/markets, Products and Product Features: Evidence from Case Studies

\begin{tabular}{|c|c|c|c|c|}
\hline & \multicolumn{2}{|c|}{$\begin{array}{l}\text { Mobile communication (early 1990s - } \\
\text { early 2000s) }\end{array}$} & \multicolumn{2}{|c|}{ Digital Imaging (printing) } \\
\hline & Motorola & Nokia & Kodak & HP \\
\hline $\begin{array}{l}\text { Beliefs about } \\
\text { customer needs } \\
\text { and markets } \\
\text { for } 1 \mathrm{G} \text { and } 2 \mathrm{G} \\
\text { phones and } \\
\text { digital images } \\
\end{array}$ & $\begin{array}{l}\text { Mobile phones } \\
\text { were products that } \\
\text { customers used for } \\
\text { improving } \\
\text { "productivity and } \\
\text { efficiency" }\end{array}$ & $\begin{array}{l}\text { Mobile phones } \\
\text { were products that } \\
\text { customers used for } \\
\text { "cultivating social } \\
\text { relationships" }\end{array}$ & $\begin{array}{l}\text { Pictures were } \\
\text { products that } \\
\text { customers used for } \\
\text { "enhancing social } \\
\text { relationships" }\end{array}$ & $\begin{array}{l}\text { Pictures were } \\
\text { products that } \\
\text { customers used for } \\
\text { enhancing } \\
\text { "creativity and } \\
\text { inventiveness" }\end{array}$ \\
\hline $\begin{array}{l}\text { Target product } \\
\text { features } \\
\text { (products and } \\
\text { product design) }\end{array}$ & $\begin{array}{l}\text { Answering } \\
\text { machine, call } \\
\text { forwarding, voice } \\
\text { mail, phone book, } \\
\text { vibration alert - } \\
\text { vibracall } \\
\text { (Clamshell design) }\end{array}$ & $\begin{array}{l}\text { Large displays and } \\
\text { keypads for SMS, } \\
\text { changeable colored } \\
\text { covers, } \\
\text { signal/battery } \\
\text { indicators } \\
\text { (Candybar design) }\end{array}$ & $\begin{array}{l}\text { Quality, cost, easy- } \\
\text { to-use } \\
\text { (Digital Kiosks for } \\
\text { printing at } \\
\text { retailers) }\end{array}$ & $\begin{array}{l}\text { Seamless integration } \\
\text { with PC and every } \\
\text { kind of digital data, } \\
\text { flexibility of output, } \\
\text { (Data printers for } \\
\text { home/office use) }\end{array}$ \\
\hline
\end{tabular}

A clear and highly consistent pattern emerged in our data. This regards the co-evolution and mutual influences, in each case industry, of two specific and very different kinds of markets for mobile phones, on the one hand, and printed images, on the other hand: these are the social market and the esteem market.

Mainstream literature defines a set of products designed to serve the same need - and

\footnotetext{
${ }^{9}$ DPI (dots per inch) is a feature directly related to the resolution graphics of color prints: printers with higher DPI generally produce clearer and more detailed outputs.
} 
market - as a 'product category' (see for instance Aaker and Keller, 1990; Lambkin and Day, 1989). For the sake of clarity, in the paper we define a class of products which customers use for addressing their need for achievements and recognition (e.g. in their work or hobby activities), as an 'esteem' product category. Accordingly, we define a group of customers that use a given product category (e.g., mobile phone) for fulfilling their need for achievement and recognition, as the "esteem market" for that product category. We define as well a class of products which customers use for addressing their need for social relationships, as a 'social' product category; and we define a group of customers that use a given product

category (e.g., mobile phone) for improving their social relationships, as the "social market" for that product category.

Our characterization of the esteem and the social markets/product categories is fully consistent with the recommendation of Christensen and colleagues (Christensen and Raynor, 2003; Christensen at al., 2004) to focus on the basic needs that customers try to satisfy through the products they use in their everyday life. We thus clearly set apart our empirical investigation from the traditional segmentation criteria used in marketing research such as age, geographic regions or income. Precisely, we borrowed the terms 'esteem' and 'social' markets from Maslow's (1954) theory on needs hierarchy, which emphasized that most of people during their lives experience both the need for social relationship (love, friendship, intimacy) and the need for esteem (achievement and results, status and recognition, respect by others): we relate a specific market/product category to each specific need.

\subsection{Technological change and the rise of new social or esteem markets}

A key issue which clearly resulted from our data is the disruptive impact that the new technologies ( $1 \mathrm{G}$ together with $2 \mathrm{G}$ in mobile communication; and digital imaging in the imaging industry) had on the mainstream markets and product categories which had been 
historically served by incumbent firms.

In both the mobile communication industry and the imaging industry the new technologies enabled completely new markets (and product categories) to emerge: the social market in the first industry, whereas the traditional market was the esteem one; and the esteem market in the second industry, whereas the traditional market was the social one. Incumbent firms (i.e. Motorola and Kodak) that previously had made either esteem products or social products were able to adopt and to launch disruptive technologies promptly. But, contrary to their challengers, incumbents were not able to renew their target markets and product categories as well: Motorola failed to select and develop the emerging social markets where customers started using mobile phones for cultivating social relationships; and Kodak failed to indentify the esteem market where customers started using printed images for improving their work or hobby achievements.

Both these rising markets were boosted by the new technologies - and could not be fulfilled by the previous mainstream technologies. Prahalad and Bettis (1986) and Kaplan and Tripsas (2008) argue that managers' prior history and experience make up the 'technological frames' through which they make sense of a (new) technology, and that these technological frames are encoded in a shared set of beliefs - commonly referred to as a 'dominant logic' that is unique to a given firm. Our findings suggest that the strategic beliefs, which managers developed about the social (or, vice versa, esteem) market/need they had traditionally served, are typical manifestations of such dominant logic. Managerial beliefs about the social (or, vice versa, esteem) market did not prevent incumbent firms from identifying and engaging with disruptive technologies; however, these mental models prevented incumbent firms from identifying the emerging esteem (or, vice versa, social) market, by restricting their search and sensemaking exactly to the social (or, vice versa, esteem) market they had served previously. 
5.1.1 Mobile Communication (early 1990s -early 2000s). To consider mobile

communication: various products - two-way radios, pagers and eventually car phones - had been developed since the 1930s to make mobile communications available anytime and anywhere. But all these devices - and their underlying mainstream radio communication technologies which preceded $1 \mathrm{G}$ and $2 \mathrm{G}$ - had clear intrinsic limits. Two-way radios allowed customers to talk only to a restricted number of people and only across a limited distance; pagers did not allow users to talk directly but required fixed-line phones, so that calls were constrained by the public nature of these phones which were usually shared with colleagues or family members; car phones were not really portable. Within their limits these devices were functional to business executives and professionals who could use them profitably for fulfilling the need to perform their work tasks on the move so as to increase their productivity (esteem market - product category - for pagers, two way radios, car phones).

Before the advent of mobile phones, Motorola had marketed exactly two-way radios (the first dating back to 1939), car phones (1946) and pagers (1956). The company still makes these products today, with its web site defining them as devices which can "help improve business productivity [...]: portable and mobile two-way radios and pagers offers solutions that better enable you to efficiently coordinate and communicate with your on-thego workforce"

At the time it started introducing its mobile phones, its 1990 annual report stresses:

In 1990 Motorola improved the way the world communicates. Drawing on the broadest portfolio of semiconductors in the world, we introduced electronics products, systems and services designed to make our customers more productive.

while the cover shows a guard using a two-way radio in front of the Louvre; the caption explains:

One of the newest landmarks in Paris is architect I.M. Pei's pyramid entrance to the Louvre. Guards from Erom Sécurité S.A. use Motorola two-way communications

\footnotetext{
${ }^{10}$ www.motorola.com, accessed November 2010.
} 
equipment at the museum to protect some of the finest art treasures in the world.

Such data show how Motorola intended its two-way radios and pagers as an esteem product category aimed at serving customers when trying to improve their achievements and recognition (i.e. 'productivity' and 'efficiency' according to Motorola). Thanks to its longstanding experience with two-way radios, pagers and car phones, Motorola had clearly developed deeply-rooted managerial beliefs about the linkages between the 'esteem' need and mobile communication technologies. So when it launched its $1 \mathrm{G}$ and $2 \mathrm{G}$ mobile phones, Motorola still addressed the same customers' need for improving work achievements and the same esteem market it had traditionally served through the previous two-way radios and pager technologies. Coherently, it selected answering machine, call forwarding, voice mail, phone book, vibracall, and ergonomic and compact 'clamshell' design as its target product features and product design for fulfilling at best this esteem market and need.

But the advent of $1 \mathrm{G}$ and $2 \mathrm{G}$ wireless technologies signaled a major shift in the need and market that mobile communication tools could address compared with two-way radios and pagers. The new $1 \mathrm{G}$ and $2 \mathrm{G}$ based mobile devices, i.e. mobile phones, solved all the limits of pagers, two-ray radios, and car phones: mobile phones were personal communication tools which enabled customers to talk one with each other directly, anytime, anywhere, so that calls could remain private and their content confidential. Mobile phones thus fostered new ways - in particular, text messages (SMS) - to pursue friendship, relationships and love: they were a sort of repository of private communications and the personal emotions linked with these communications. This concept of mobile phones as a new product category which customers could use for enhancing their social relationships, was exactly at the heart of Nokia's design vision:

A mobile phone, device or enhancement is much more than a piece of electronics: it is a personal object. You keep it close to you, you tell it personal and intimate things, you use it when and where you want. It reflects your mood and personality and is in tune with your interests and attitudes. All of this separates it from the world of wired products, fixed 
locations and the conventions of how things have been done. All this makes it an object that embraces innovation and design and is a reflection of the changing lives we live. ${ }^{11}$

5.1.2 Digital imaging (printing). During the $20^{\text {th }}$ century the analog technology of the camera and roll film system had opened the doors to the mass production of images and created a large amateur market of customers as photographers. But this technological paradigm had still limited what people could do in terms of elaborating and using images: roll film system required ordinary customers to print their images without any substantial modification and to store them in picture frames or albums to share with family and friends visiting their homes. Analogue film technology thus was well-suited to private moments and personal events, a perfect example of answering the need for social relationships.

During the $20^{\text {th }}$ century, Kodak had pioneered the camera and roll film system. Thanks such longstanding experience, Kodak had clearly inherited deeply-rooted managerial beliefs about the linkages between the social market for pictures and imaging technologies. As a result, when it had to commercialize digital imaging, Kodak aimed to enable people to make images celebrating important moments of their personal lives and invested in kiosks at retailers where they could continue to get high quality pictures to store in picture frames or albums: this was exactly the social product category, i.e., social market of printed images, that the company had traditionally served within the previous film technological paradigm.

But digital technologies brought a strong discontinuity compared with the film technology. Digital technologies enabled customers to use images as any other form of data: as data, images became a relevant component of the digital stream of knowledge creation and dissemination. Digital images represented an immediate and universal language through which people could express, store and manipulate their ideas, by seamlessly embedding and printing them in the files (e.g.. Microsoft Word documents or Power Point presentations) they used for improving the results and achievements of their work or hobby activities. This is

\footnotetext{
${ }^{11}$ Nokia Design internal report, 'Nokia Design leads the way'.
} 
exactly the emerging esteem product category inherent in digital images which HP served through its data printers for home or office use. In the previous section we defined a group of customers that use a given product category (e.g., mobile communication devices) for fulfilling their need for achievement (or, vice versa, their need for social relationship), as the "esteem" (or, vice versa, "social") market for this product category. Consistent with this definition, we suggest:

Proposition 1: Disruptive technologies are likely to enable the rise of the new social (or, vice versa, esteem) market for a product category that, through previous technologies, could satisfy only the esteem (or, vice versa, social) market. ${ }^{12}$

Proposition 2: Incumbent firms that historically used a product category to address the esteem (or, vice versa, social) market are likely to hold strong beliefs about this esteem (social) market.

Proposition 3: In the face of disruptive technologies, incumbent firms that historically used a product category to address the esteem (or, vice versa, social) market are less likely than newcomers to use the same product category for addressing the new social (or, vice versa, esteem) market.

\subsection{Disruptive innovation dynamics in social and esteem markets}

In both our case industries, the products that were designed for the new and emerging social (or, vice versa, esteem) market evolved so that they disrupted the products designed for the mainstream esteem (or, vice versa, social) market. We describe here the disruptive dynamics which affected the social market vs. the esteem market for mobile phones and printed images. Following Christensen (1997) pioneer work on the disk drive industry, we focus on: a) the trajectory of the performance customers demanded for the mainstream feature in the traditional esteem market for mobile phones (and the traditional social market for printed images); b) the trajectory of the performance customers demanded for the mainstream feature

\footnotetext{
${ }^{12}$ For the sake of clarity, "to enable the rise of the social market for a product category" means that (disruptive technologies) enable customers to use a given product category, e.g. mobile communication devices, for fulfilling their need for social relationship, whereas historically this product category could not be used conveniently for keeping in touch with family or friends. Contextually, "satisfy only the esteem market" means that (previous technologies) historically enabled customers to use conveniently a given product category - e.g., mobile communication devices - only for fulfilling their need for achievement.
} 
in the emerging social market for mobile phones (and the emerging esteem market for printed images); c) the trajectory of the performance provided for the mainstream feature by the clamshell products Motorola designed for the traditional esteem market for mobile phones (and by the kiosks Kodak designed for the traditional social market for printed images); and d) the trajectory of the performance provided for the mainstream feature by the candybar products Nokia designed for the emerging social market for mobile phones (and by the home/office printers HP designed for the emerging esteem market for printed images).

All together, these trajectories had a key role in the decline of established firms and the rise of their rivals. When Motorola and Kodak, on the one hand, and Nokia and HP, on the other hand, started commercializing the new technologies, the performance customers demanded for mainstream features (i.e., weight for mobile phones and quality for printed images) in the traditional market (i.e. esteem in the case of mobile devices and social in the case of printed images) were considerably different from the performances that customers demanded in the emerging market (i.e. social in the case of mobile phones and esteem in the case of printed images). Similarly, the performances provided for mainstream features by the products designed by incumbents firms and the products designed by their rival firms were different: the clamshell phones designed by Motorola were more lightweight than Nokia's candybar phones and the quality (DPI) of the printed images provided by Kodak's kiosks was superior than the quality of the printed images provided by HP's home or office data printers. Initially, in both industries these differences in performance trajectories kept separated the esteem market from the social one. However, in both the mobile communication and the imaging industries, the product solutions designed by Nokia and HP evolved over time so that they eventually matched the requirements for mainstream features in the traditional markets targeted by Motorola and Kodak. This paved the way for the migration of Motorola's and Kodak's customers to their rivals Nokia and HP. 
Maslow (1954) emphasized that most of people during their lives experience both the need for social relationships and the need for esteem: indeed most human beings are members of both a) a family and a social network in which they aim at enhancing their feelings of love and friendship; b) an organization in which they carry out work or hobby activities for enhancing their achievements, status and recognition. This means that most people need both products for enhancing their social relationships and products for enhancing their esteem. As a result, it is clear that when Nokia's candybar phones and HP printers enabled users to fulfill both their social need for relationships and esteem need for achievements, these phones and printers appealed to Motorola's and Kodak's mainstream customers.

5.2.1 Mobile communication (early 1990s -early 2000s). The case of mobile communication illustrates very well disruptive dynamics in social and esteem markets. Figure 1 plots the evolution of the mainstream feature (weight of mobile phones) achieved by Motorola and Nokia through their hallmark clamshell and candy-bar design concepts. It's worth emphasizing that these different product designs were strictly linked with the product features each company wanted to offer according to its target market (and related need to be served) for mobile devices. These product features were weight, size and easy handling for Motorola and the esteem market; large keypads and displays for easy writing of SMS and changeable covers in fashionable colors for Nokia and the social market. (It is worth noting also that the price of Motorola's clamshell products considerably decreased throughout the late 1990s and early 2000s, so being comparable to Nokia 'candybar models).

Figure 1. Mobile Communication (early 1990s - early 2000s): Patterns of Improvement in Mainstream Product Feature (Weight): Motorola's Clamshell Products vs. Nokia's Candybar Products ${ }^{13}$

\footnotetext{
${ }^{13}$ The trajectories in Figure 1 were derived from the main products that developed from the late 1980s until the early 2000s, the design concept of each company and its related product features. These products are: in case of Motorola, MicroTAC 9800X (released in 1989, weighing 348 grams), MicroTAC Lite (1991, 218g), MicroTAC Classic (1991, 196g), MicroTAC Ultratite (1992, 167g), MicroTAC Elite (1994, 111g), StartTAC (1996, 88),
} 


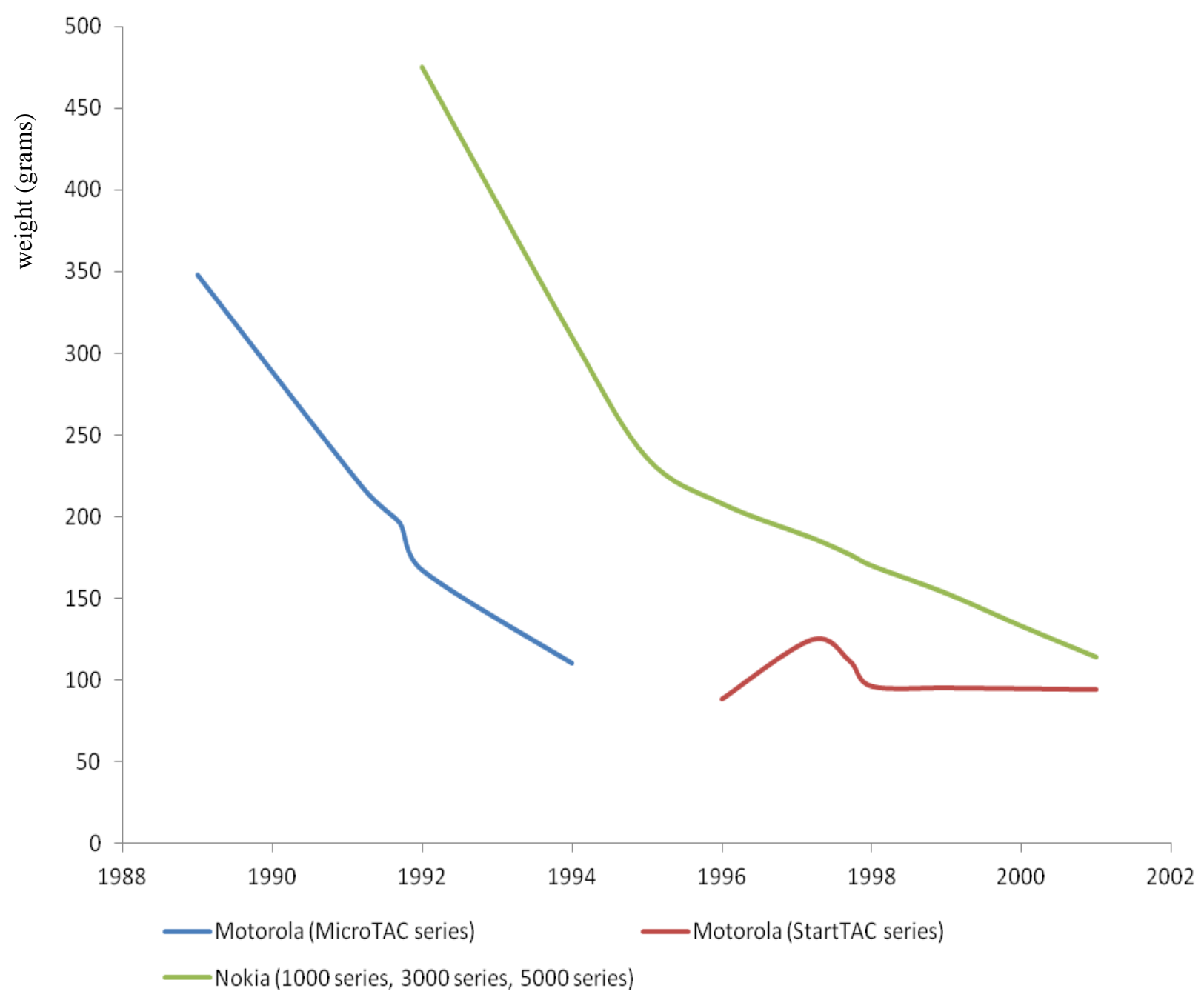

Year

Figure 1 shows that Nokia's products were able to approximate over time the weight performance of Motorola's ones. Nokia could easily embed as well Motorola's additional features (e.g., vibracall, voice mail, call forwarding) into its products, allowing them to fulfill both customers' demand for productivity (esteem market of mobile devices) and their growing demand for social relationship (social market).

Table 5 illustrates Nokia's and Motorola's global market share between 1996 and 2001. Global market data clearly show that Motorola's target customers quickly shifted towards

StarTAC 70 (1997, 125g), StarTAC 75 (1997, 112g), StarTAC 130 (1998, 95g); in case of Nokia, 1011 (1992, 475g), 2110 (1995, 236g), 3110 (1997, 187g), 5110 (1998, 170g), 3210 (1999, 153g); 3310 (2000, 133g), 3410 (2001, 114g).

The slight increase of weight in the StarTAC series between 1996 and 1997 is due to the shift from analog (1G) to digital $(2 \mathrm{G})$ wireless technologies. 
Nokia: Nokia surpassed Motorola in 1998, and by 2000 its market share had risen to 31\%, more than twice Motorola's, driven by such hallmark (candy-bar: see Figure 1) models as the 3210 (released in 1999) and its successor the 3310 (released in 2000) which sold respectively 160 million and 129 million units, against a background of total mobile phone shipments of 284 million in 1999 and 413 in 2000 (399 in 2001). ${ }^{14}$ A senior Nokia manager commented on the success of the 3210 and 3310 models: "With their stylish features they appealed to both the business and consumer segments. The amazing thing was the extreme heterogeneity of the actual customers for these products, ranging from top managers to students, from professionals to teenagers". Remarkably, Nokia was able to outpace Motoroloa not only in the EU market but also in the US. In the latter country the $2 \mathrm{G}$ wireless technologies had more gradual adoption rate than in the EU, so that the price of mobile phones and their fees were relatively higher and business users were much longer the largest element of the market: however, Nokia surpassed Motorola in the US market in 2000 and reached a record 35\% market share in 2002.

Table 5. Global Market Share of Motorola and Nokia (1996-2001) (Source: Gartner)

\begin{tabular}{lcccccc}
\hline & $\mathbf{1 9 9 6}$ & $\mathbf{1 9 9 7}$ & $\mathbf{1 9 9 8}$ & $\mathbf{1 9 9 9}$ & $\mathbf{2 0 0 0}$ & $\mathbf{2 0 0 1}$ \\
\hline Motorola & 27.0 & 28.8 & 23.2 & 16.9 & 14.6 & 14.8 \\
\hline Nokia & 21.0 & 20.1 & 24.3 & 26.9 & 30.6 & 35.0 \\
\hline
\end{tabular}

On the basis of the empirical data reported in Figure 1 and Table 5, Figure 2 illustrates patterns of competition in the mobile communication industry. We plot: i) the performance trajectories provided by both Motorola's clamshell and Nokia candybar products; ii) and the performance trajectories demanded by customers for the mainstream feature - weight - in the esteem market for mobile phones and in the social market. The framework of the figure is taken from Christensen's focal illustration of disruptive technologies in the disk drive

\footnotetext{
${ }^{14}$ Data on market share and shipments in the mobile communication industry are drawn from IDC Consulting and Gartner Inc.
} 
industry (see Christensen and Bower, 1996: 204): the main difference is that we focus on the performance trajectories related to product design concepts, meant for either the disruptive social market or the mainstream esteem market, rather than on technologies. The blue dotted trajectory B represents the average weight performance demanded by customers who used mobile phones in the esteem market targeted by Motorola; the black dotted trajectory C represents the average weight performance demanded by customers in the social market targeted by Nokia. The red solid line trajectory A measures the performance provided for weight by Motorola's clamshell products, while the solid green line trajectory D measures the performance provided for weight by Nokia's candybar phones. According to empirical data, mainstream customers from the esteem market definitely migrated to Nokia's products in 1998, when the performance trajectory they demanded for weight (trajectory B) and the performance trajectory provided by Nokia's candybar phones (trajectory D) intersected: this is the time when the emerging social product category (i.e. Nokia's candybar phones targeted at the social need) disrupted the traditional esteem product category (i.e. Motorola's clamshell phones targeted at the esteem need). Note that, compared with Figure 1, Figure 2 plots the weight-related performance of Motorola's and Nokia's mobile devices instead of their weight itself: a decrease in weight is thereby associated with an increase in performance. The performance trajectories of Figure 2 represent the symmetric functions of the trajectories of Figure 1: for the sake of clarity of the diagram, the axis of symmetry has been fixed at 350 grams with respect to the $\mathrm{x}$-axis.

Figure 2. Mobile Communication (1992 -2001): Patterns of Improvement in Product Design Architectures and Performance Trajectories Demanded by Customers in the Esteem and Social Markets for Mobile Phones 


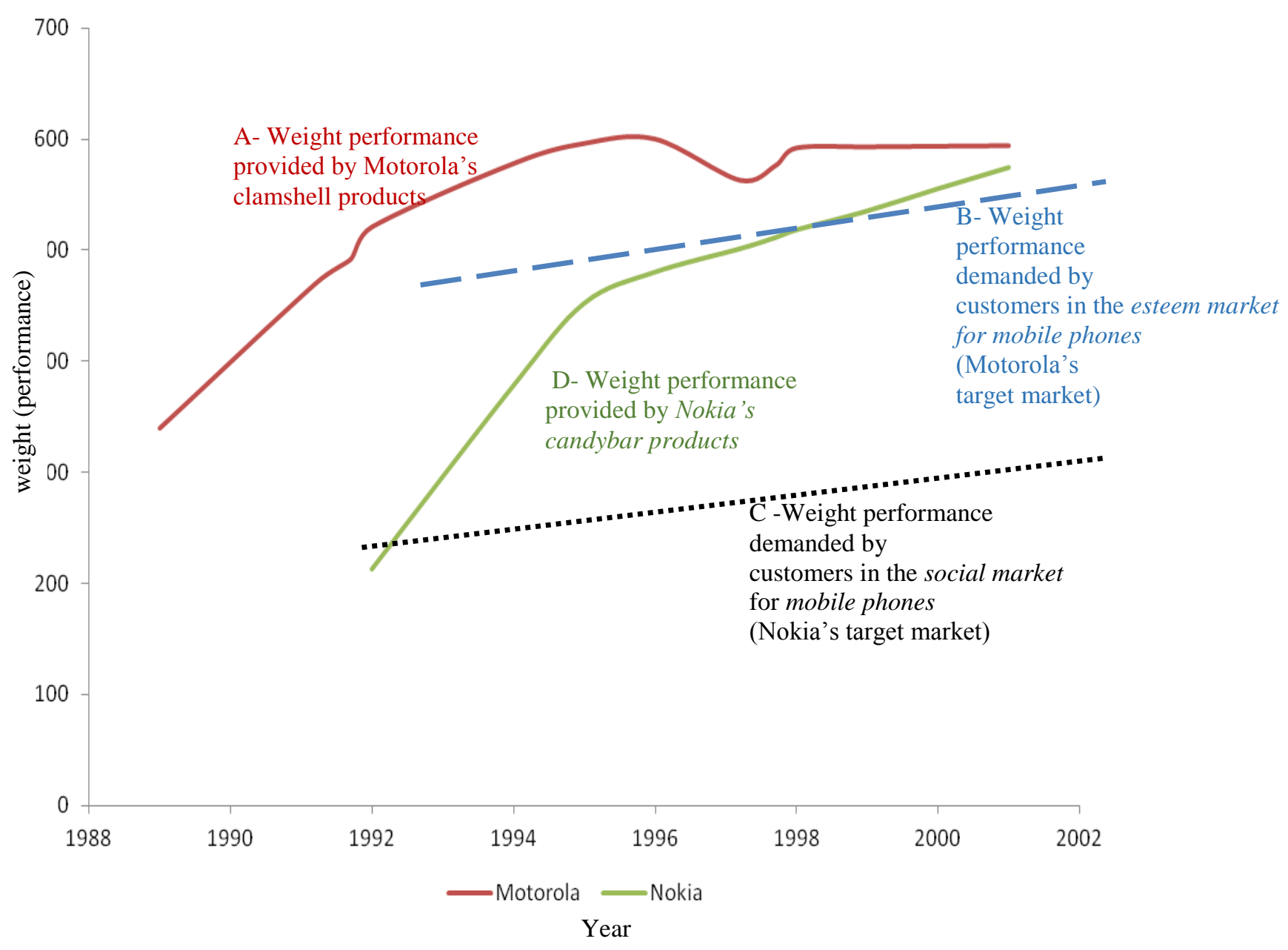

5.2.2 Imaging (printing). The history of hard-copy image printing is also very revealing. Our data suggest that the products - data printers for home and office use - HP designed to serve customers in the esteem market for printed images (images as esteem product category) evolved over time to the point where the mainstream feature (i.e. image quality) matched the performance demanded by customers in the traditional social market (images as tools for sharing memories: social product category). The quality of HP's printers (in terms of DPI dots per inch) improved from 2,400x 1,200 in 2001 (e.g., the Photosmart 1315 model) to 4,800x 1,200 in the mid 2000s (e.g., Photosmart 3210) and to 9,600x2,400 in 2008 (e.g., Photosmart CQ521B) so that it matched and even exceeded the quality performance provided by the Picture Maker Kiosks Kodak released in the early 2000s. The average customers that Kodak's targeted in relation to the social market for printed images, thereby, could start using HP's home and office printers to make the high quality pictures they required. As HP's 
former CEO Carly Fiorina claimed:

Take digital photos of your daughter's soccer game or your son's play, and conveniently print them at home, all for the same price that it takes to print them at your local retailer - today, you can [...]. This is a story of digital experiences that are affordable, easy to use, and work seamlessly together. ${ }^{15}$

and its 2007 annual report emphasized:

An important part of IPG's [Imaging and Printing Group] strategy is to provide digital imaging solutions that rival traditional imaging for quality, cost and ease of use so that consumers can manage their digital imaging throughout the home and outside the home.

This paved the way for HP to establish itself as the definitive market leader in image printing: customers could use its home and office printers for making both the digital pictures they required for the esteem need to enhance their achievements and the social need to share their personal events with family and friends. The popularity and success of HP products (home and office printers) quickly grew and largely surpassed Kodak’s kiosks. Again, industry evolution data are very instructive: many marketing research companies (i.e. PMA, IDC, Infotrends) stressed the role of home and office printing (and thereby of home and office data printers) as the dominant method used by customers in the late $2000 \mathrm{~s}$ - in both the US and the EU - to create digital photo prints. Home and office printing surpassed retail printing (and thereby kiosks) in terms of volume, revenues, and profits. ${ }^{16}$ Today as well customers generally use home printing for frequent making of small volumes of pictures, while they might use retailers for less frequent printing of larger volumes.mOverall our findings suggest the following propositions:

Proposition 4: In the face of disruptive technologies, the performance level of the mainstream features that customers demand in the emerging social (or, vice versa the emerging esteem) market is likely to be inferior to the performance level they demand in the traditional esteem (or, vice versa, the traditional social) market.

\footnotetext{
${ }^{15}$ Carly Fiorina, 'The digital experience journey'. HP Digital Experience press conference, Miami, Florida, August 27, 2004. It is worth noting that the price performance of the incumbent's business model was superior to that of the challenger's.

${ }^{16}$ Sources: IDC, PMA Marketing Research, InfoTrends, BBC Research. All these marketing companies publish annual reports capturing emerging trends in the digital photo industry, with specific sections about prints and printing behaviors. Selected data are available on the website of each company.
} 
Proposition 5: Incumbent firms that design products for the traditional esteem (or, vice versa, the traditional social) market, are likely to sustain their leadership in the short run.

Proposition 6: Entrant firms that design products for the emerging social (or, vice versa, the emerging esteem) market and that develop these products so that they satisfy the performance level of the mainstream features required in the traditional esteem (or, vice versa, the traditional social) market, are likely to establish as the long-term.

\section{Discussion}

The main contribution of this paper is to expand our understanding of the disruptive innovation theory with regard to the key issue of why incumbent firms fail to identify emerging markets, products and product features (Christensen 1997; Charitou and Markides, 2003; Sabatier et al., 2012). Building on the efforts of previous scholars in the field of cognition, we explore how managers develop over time their strategic beliefs about customers needs and we show the importance of these beliefs in directing the market responses of incumbents to disruptive technological change (Henderson, 2006; Osiyevskyy and Dewald, 2015). Overall, we thus add to the study of the implications of disruptive innovation for established firms, new entrants, customers, and entire business ecosystems.

Christensen and Raynor (2003) urged practitioners and scholars to look for the "jobs", i.e., the basic needs, that customers try to get done through the products they use in everyday life, by arguing that these basic needs are the cornerstone for the successful selection of new markets in the face of disruptive technologies. However, Christensen and colleagues did not identify well-defined cases of basic needs (and related markets) which are systematically affected by disruptive innovation.

Our work bridges exactly this gap. We identify the social and esteem markets for mobile communication devices and images, i.e., the social and esteem needs that customers try to get done by means of both these classes of products. We show that because senior managers of Motorola (Kodak) had contributed to the establishment of previous technologies serving only the esteem (social) need/market, they held strong beliefs about this esteem (social) market. 
Such strategic beliefs were the typical manifestation of the 'dominant logic' described by Prahalad and Bettis (1986) and Kaplan and Tripsas (2008): they prevented Motorola's (Kodak's) managers from selecting the new social (esteem) market where disruptive technologies could be successfully used (Henderson, 2006).

We suggest that, similarly to the cases of the mobile communication and the imaging businesses, in several high-tech industries established technologies -and related products might be currently serving only either the esteem or the social basic need of customers. Thereby, similarly to Motorola and Kodak, the managers of incumbent firms in these industries might hold strong beliefs about either the esteem or social market they have historically served. In the face of disruptive technologies, the future success - or even survival - of these firms thus depends on the capability of their top managers to recognize and change such markets and strategic beliefs: our findings in this paper represent a first, essential toward this change.

Figure 3 sums up our conceptual framework on the relationship between managerial beliefs, social and esteem markets, and competition outcomes. 
Figure 3. Disruptive technologies, social and esteem markets, managerial beliefs, and competition outcomes

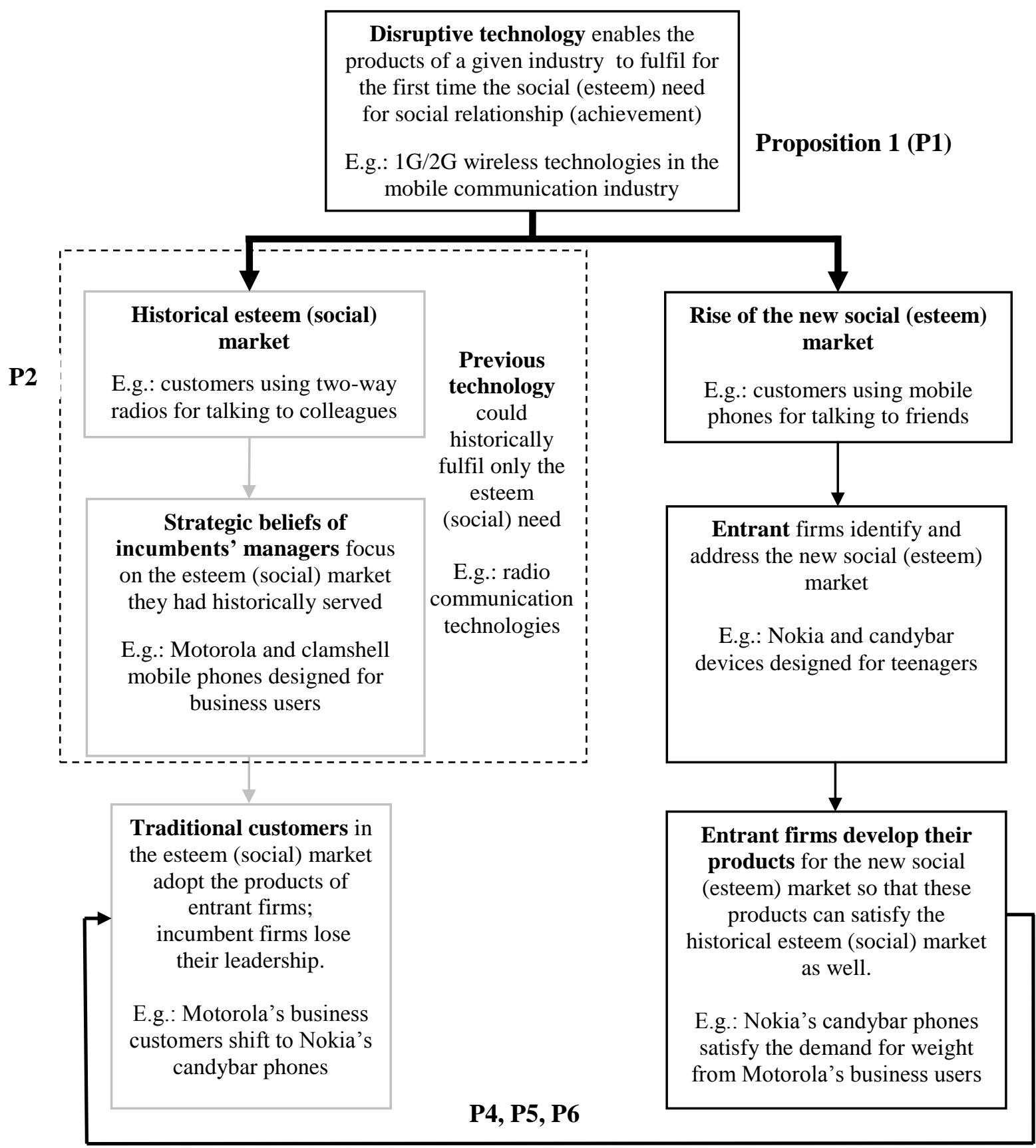

Market disruption and long-term technology competition outcomes: entrant firms become the new leaders

At the same time, through our conceptual framework we aim at improving the use of the disruptive innovation theory with regard to the anticipation of technology competition outcomes (Christensen et al., 2004; Dixon et al., 2014; Govindarajan and Kopalle, 2006). As 
we recognize that the social (or, vice versa, esteem) product category is going to emerge in an industry where customers traditionally used products for fulfilling their esteem (or, vice versa, social) need, we can anticipate the likely disruption of the esteem (or, vice versa, social) market and the decline of incumbents. We argue that this might be the case today once again - of the mobile communication business, after Microsoft launched in 2015 its new Windows 10 Mobile operating system.

In late 2016, i.e., one year after its launch, Windows is still relegated to a very small market niche within the smartphone business (less than $3 \%$ worldwide): according to Microsoft's top managers themselves, the main reason is the lack of applications ('apps') compared with the leading operating system iOS and Android which are provided respectively by Apple and Google. ${ }^{17}$ However, the new Microsoft' Windows 10 platform is aimed at providing a fully unified operating system for PCs, tablets and smartphones, so enabling developers to write a single application and have it run across every form factor (PCs, tablets, smartphones). Windows 10 Mobile-based smartphones thereby are designed to be seamlessly and fully compatible with the productivity applications, programs, files and data (e.g., Microsoft Excel spreadsheets, Word processor files, PowerPoint presentations, Outlook contacts, agenda and emails) that customers run on their PCs for their work (or hobby) activities. Windows 10 Mobile also is designed to allow developers to easily port their applications from the current leading platforms, i.e., Google's Android and Apple' iOS. According to the conceptual framework we illustrate in this paper, we argue that the Windows 10 Mobile platform is likely to enable smartphones to serve a new kind of need and market, i.e. the esteem need and the esteem market: customers will be gradually able to use

\footnotetext{
${ }^{17}$ See for instance M. Weinberger, 'Steve Ballmer says Microsoft CEO Satya Nadella's big initiative won't work", Business Insider UK, December 2, 2015. Indeed, in early 2015 Windows Phone featured about 300,000 apps against Google's Android 1,3million apps and Apple's iOS 1,3million apps. Most remarkably, many Windows Phone apps were inferior in terms of technical features compared with the 'twin' apps available for iOS and Android and were released considerably later: for instance, the early version of the official Instagram app for windows Phone was released just in November 2013.
} 
smartphones for improving their achievements and performances, by fully accessing (and editing) their PC files, data, and applications anytime and anywhere. The rise of the esteem market (and related need) could represent a deep discontinuity in the smartphone industry: the most popular 'apps' for smartphone devices (e.g. Facebook, Instagram, WhatsApp) are related so far to social networks, photo streaming, video chatting, cross-platform messaging. These apps clearly took advantage of mobile Internet in order to enhance people's social relationships (so that they addressed the historical social market for smartphones).

We argue that Microsoft Windows 10 Mobile-based smartphones should initially appeal to professionals and business users. Afterwards, if Microsoft is actually able to establish Windows 10 in the PC industry and contextually to increase the number of apps running on its Windows 10 mobile-based smartphones, the company will match as well customers' demand for social relationships. We thus suggest to monitor closely the number of apps that are being released for Windows 10 Mobile: if this number is going to increase significantly so that it can bridge the gap with the Android's and iOS' ecosystems, Microsoft is likely to disrupt Apple and, most of all, Google. (It is worth noting that due to their flawed or partial compatibility with the Windows-based PCs most customers use for their work activities, iOS and Android could satisfy at best only customers' demand for social relationships so far - i.e. they could only support the historical use of smartphones as a social product category).

Figure 3 summarizes our anticipation of the evolution of the mobile communication business from today (late 2016) until the next few years (2021). The number of 'apps' is the mainstream feature in the mainstream social market for smartphones and the emerging esteem market. Trajectory A represents the number of apps provided by Apple's iOS- and Google's Android- based smartphones; trajectory B represents the number of apps demanded by mainstream customers in the social market for smartphones. Trajectory $\mathrm{C}$ represents the number of apps demanded by customers in the emerging esteem market for smartphones; 
trajectory $\mathrm{D}$ is the number of apps provided by Windows 10 -Mobile based smartphones.

Disruption between competing operating systems should occur in $\mathrm{T}^{*}$, when (and if) the performance trajectory of apps demanded by customers in the social market (trajectory B) and the performance trajectory of apps provided by Microsoft's Windows 10-based smartphones (trajectory C) intersect.

Figure 4. Mobile Communication (Smartphones): Predicted Evolution (2015 -2021)

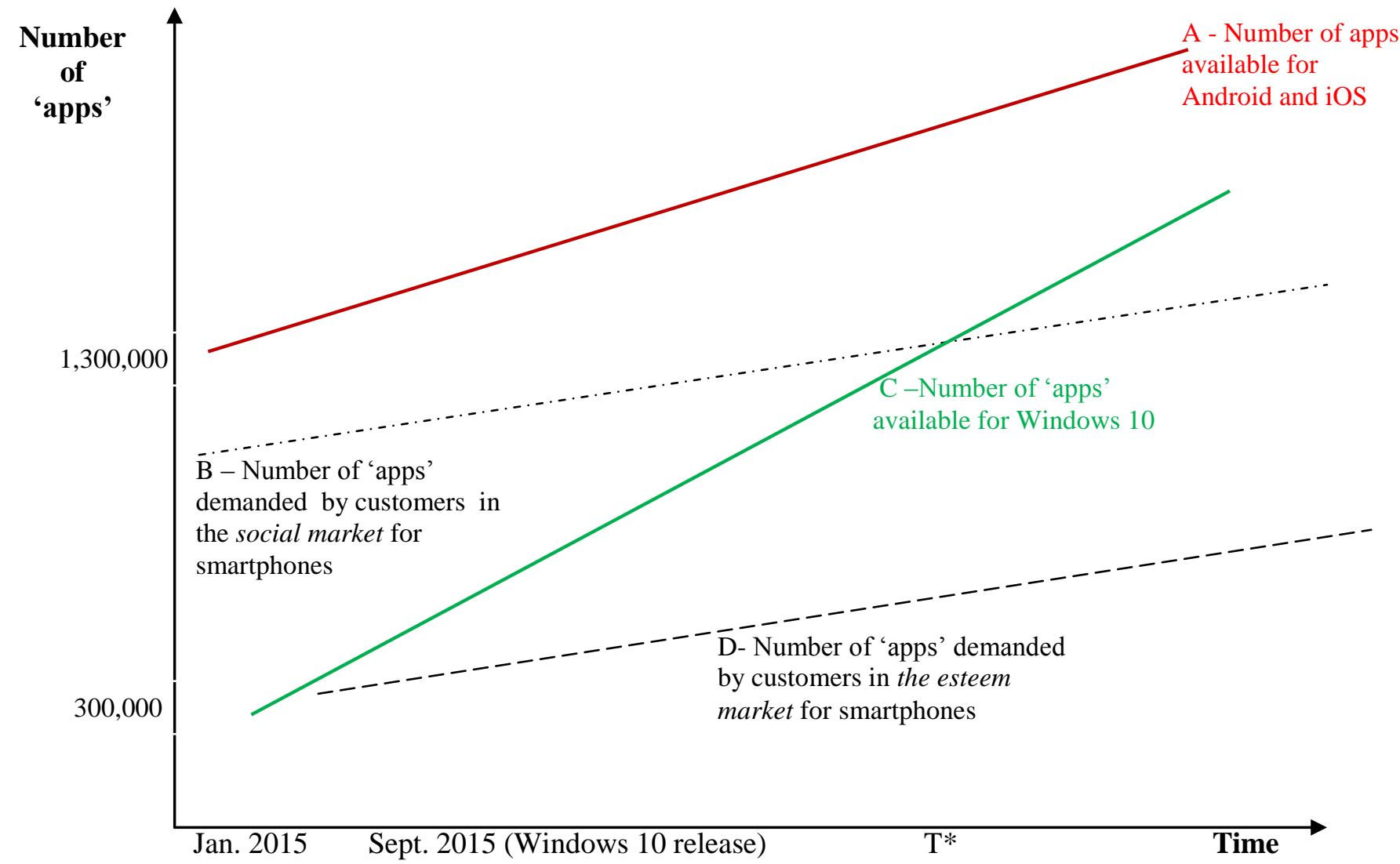

\section{Conclusions}

This paper crosses research fields on disruptive innovation and managerial cognition in order to expand our understanding of the reason why incumbent firms show inflexible market positioning in the face of technological change, i.e. why they fail to identify new markets for

\footnotetext{
${ }^{18}$ See previous note for data about the number of 'apps' available for the iOS, Android, and Windows ecosystems.
} 
the commercialization of disruptive technologies.

As we focus on the mobile communication industry (together with the case of digital imaging), we bring a fresh perspective on competition outcomes in this industry between the early 1990s and the early 2000s. The rise of Nokia over Motorola has been largely studied in literature on innovation: before us, scholars focused in particular on the role in such rise of geographically differentiated markets (US vs. EU) and standards (2G vs.1G) (Berggren and Laestadius, 2003; Steinbock, 2001). Our research aims to complement the work of previous scholars, by exploring the role of disruptive innovation instead. Furthermore, our research explores current and future competition outcomes in the fast-paced mobile communication business.

We borrow our definition of esteem and social product categories from Maslow's hierarchy of needs (Maslow, 1954). We suggest that future research efforts of scholars should build on Maslow's classification of needs (i.e. physiological, safety, social relationships, esteem, and self-actualization) in order to identify and investigate new pairs of markets for everyday life products which are subject to mutual disruption over time, exactly as the cases of social and esteem markets/products.

Our research setting, data collection, and data analysis were designed to enhance the construct and internal validity of our theoretical framework. Data triangulation between different sources and pattern-matching across multiple cases (literal replication) improved the reliability and external validity of our propositions (Yin, 2003). At the same time, in terms of robustness and generalization, it is critical to note that our work is based on a limited number of companies: the usual limitations of case study research apply thereby to our work. We selected our theoretical sample according to the main purpose of this paper that is, as typical of case study research, to develop theory (Eisenhardt, 1989). The next step is to test our conceptual framework empirically by means of more cases and thus through a statistical (e.g., 
random or stratified) sample, so that our research propositions can be eventually generalized (Eisenhardt and Graebner, 2007).

Christensen (2006) and Danneels (2004) emphasize that a crucial theme for research on disruptive innovation regards the capability of this theory to make ex-ante predictions. In order to emphasize the relevance of our conceptual framework and its contribution to the disruptive innovation theory, we considered the recent launch of Windows 10 Mobile by Microsoft and we tried to outline future competition outcomes between this platform and the iOS and Android systems that are the currently leading the industry. We believe that the case of the smartphone industry provides a compelling setting for future research efforts on disruptive innovation and the rise of the social and esteem markets. 


\section{References}

Aaker, D.A, Keller, K.L.. 1990. Consumer evaluations of brand extensions. Journal of Marketing 54, 27-41.

Abernathy, W.J., Clark, C.K. 1985. Innovation: Mapping the winds of creative destruction. Research Policy, 14, 3-22.

Adner, R. 2002. When are technologies disruptive? A demand-based view of the emergence of competition. Strategic Management Journal 23, 667-688.

Aldenderfer, M. S., Blashfield, R. K. 1984. Cluster Analysis. Sage: Beverly Hills, CA.

Barney, J.B. 1991. Firm resources and sustained competitive advantage. Journal of Management 17, 99-120.

Barr, P. S., Stimpert, J. L., Huff, A. S. 1992. Cognitive change, strategic action, and organizational renewal. Strategic Management Journal, 13, 15-36.

Berggren, C., Laestadius, S. 2003. Co-development and Composite Clusters - the Secular Strength of Nordic Telecommunications. Industrial and Corporate Change 12, 91-114

Charitou, C.D. Markides, C.C. 2003. Responses to disruptive strategic innovation. MIT Sloan Management Review 44, 55-63.

Christensen, C. M. 1997. The Innovator's Dilemma. Harvard University Press, Boston.

Christensen, C. M. 2000. The Innovator's Dilemma. Harvard University Press, Boston.

Christensen, C. M. 2006. The ongoing process of building a theory of disruption. Journal of Product Innovation Management 23, 39-55.

Christensen, C. M., Anthony, S. D., Roth, E.A. 2004. Seeing what's next. Harvard University Press, Boston.

Christensen, C. M., Bower, J.L. 1996. Customer Power, Strategic Investment, and the Failure of Leading Firms. Strategic Management Journal 17, 197-218.

Christensen, C. M., Raynor, M.E. 2003. The Innovator's Solution. Harvard University Press, Boston.

Danneels, E. 2004. Disruptive Technology Reconsidered: A Critique and Research Agenda. Journal of Product Innovation Management 2, 246-258.

Dickson, P.R., Ginter, J.L. (1987). Market segmentation, product differentiation, and marketing startegy. Journal of Marketing, 51: 1-10.

Dixon, T., Eames, M., Britnell, J., Watson, G.B, Hunt, M. 2014. Urban retrofitting: Identifying disruptive and sustaining technologies using performative and foresight techniques.Technological Forecasting and Social Change, 89, 131 -144.

Eggers, J. P., Kaplan, S. 2009. Cognition and renewal: Comparing CEO and organizational effects on incumbent adaptation to technical change. Organization Science, 20, 461477.

Eisenhardt, K.M. 1989. Building theories from case study research. Academy of Management Review 14, 532-550.

Eisenhardt, K.M., Graebner, M.E. 2007. Theory Building form cases: opportunities and challenges. Academy of Management Journal 50, 25-32.

Garud, R., Rappa, M. A. 1994. A socio-cognitive model of technology evolution: the case of cochlear implants. Organization Science, 5, 344-62.

Glaser, B. G., Strauss, A.L. 1967. The Discovery of Grounded Theory. Aldine, Chicago.

Govindarajan, V., Kopalle, P.K. 2006. The usefulness of measuring disruptiveness of innovations ex post in making ex ante predictions. Journal of Product Innovation Management 23, 12-18.

Groen, A.J., van der Sijde, P, Walsh, S. 2008. Guest Editors' Introduction : Entrepreneurship's Role in Commercializing Disruptive Technologies. International Small Business Journal, 26, 5-7. 
Hang, C.C., Garnsey, E., Yin, E. 2015. Disruptive Innovation and entrepreneurial opportunity. Technovation, forthcoming

He, Z. L., Lim, K., Wong, P.K. 2006. Entry models and competitive dynamics in the mobile telecommunications market. Research Policy 35, 1147-1165.

Henderson, R. M. 2006. The Innovator's Dilemma as a Problem of Organizational Competence. Journal of Product Innovation Management 23, 5-11.

Kaplan, S. 2008. Cognition, capabilities and incentives: Assessing firm response to the fiberoptic revolution. Academy of Management Journal, 51: 672-695.

Kaplan, S., Murray, F., Henderson, R. M. 2003. Discontinuities and senior management: Assessing the role of recognition in pharmaceutical firm response to biotechnology. Industrial and Corporate Change, 12: 203-233.

Kaplan, S., Tripsas, M. 2008. Thinking about technology: applying a cognitive lens to technical change. Research Policy 37, 790-805.

Keller, A., Hüsig, S. 2009. Ex ante identification of disruptive innovations in the software industry applied to web applications: the case of Microsoft's vs. Google's office applications. Technological Forecasting and Social Change 76, 1044-1054.

Kogut, B., Zander, U. 1992. Knowledge of the firm, combinative capabilities, and the replication of technologies. Organization Science 3, 383-397.

Kostoff R.N., Boylan, R., Simons G.R. 2004. Disruptive technology roadmaps. Technological Forecasting and Social Change, 71, 141-159.

Lambkin, M., Day, G.S. 1989. Evolutionary processes in competitive markets: beyond the product life cycle. Journal of Marketing 53, 4-20.

Linton, J. Determining demand, supply, and pricing for emerging markets based on disruptive process technologies. Technological Forecasting and Social Change, 71, $105-120$.

Maslow, A. 1954. Motivation and personality. Harper and Row, New York

Osiyevskyy O, Dewald, J. 2015. Explorative versus Exploitative Business Model Change: The Cognitive Antecedents of Firm-Level Responses to Disruptive Innovation. Strategic Entrepreneurship Journal, 9: 58-78.

Phillips, F. Y. 2001. Market-Oriented Technology Management: Innovating for Profit in Entrepreneurial Times. Springer-Verlag, Heidelberg.

Prahalad, C.K., Bettis, R. 1986. The dominant logic: a new linkage between diversity and performance. Strategic Management Journal 7, 485-501.

Rerup, C. 2009. Attentional triangulation: Learning from unexpected rare crises. Organization Science, 20, 876-893.

Sabatier, V., Craig-Kennard A., Mangematin, V. When technological discontinuities and disruptive business models challenge dominant industry logics: insights from the drugs industry, Technological Forecasting and Social Change, 79, 949-962

Simon, H. A. 1955. A behavioral model of rational choice. Quarterly Journal of Economics 69, 99-118.

Steinbock, D. 2001. The Nokia Revolution. Amacon, New York.

Tripsas, M., Gavetti, G. 2000. Capabilities, cognition, and inertia: evidence from digital imaging. Strategic Management Journal, 21: 1147-1162.

Walsh, S.T., Boylan R.L., McDermott, C., Paulson A. 2005. The semiconductor silicon industry roadmap: Epochs driven by the dynamics between disruptive technologies and core competencies. Technological Forecasting and Social Change, 72, 213-236.

Yin, R. K. 2003. Case study research: Design and methods, 3rd ed. Sage, Thousand Oaks. 